\title{
Stable microfluidized bacterial cellulose suspension
}

\author{
Fabia K. Andrade (1) - João Paulo S. Morais (1) C Celli R. Muniz (i) \\ José Heriberto O. Nascimento - Rodrigo S. Vieira (D) Francisco Miguel P. Gama (1) \\ Morsyleide F. Rosa $\mathbb{D}$
}

Received: 16 October 2018/Accepted: 15 May 2019/Published online: 22 May 2019

(C) Springer Nature B.V. 2019

\begin{abstract}
In this work, nanofibrillated suspensions of bacterial cellulose (BC) were produced via microfluidization. The effects of the size of the openings of the microfluidizer chamber and ultrasonication on the nanofibril properties were evaluated. The results of the X-ray diffraction analysis indicated a considerable reduction in BC crystallinity (86-65\%) and crystallite size $(5.8-4.0 \mathrm{~nm})$ after microfluidization and ultrasonication. Thermal analysis showed a remarkable reduction from 337 to $283{ }^{\circ} \mathrm{C}$ in the initial
\end{abstract}

Electronic supplementary material The online version of this article (https://doi.org/10.1007/s10570-019-02512-y) contains supplementary material, which is available to authorized users.

F. K. Andrade · C. R. Muniz · M. F. Rosa ( $₫)$

Embrapa Agroindústria Tropical - CNPAT, Rua Dra. Sara

Mesquita 2270, Planalto do Pici, Fortaleza,

CE 60511-110, Brazil

e-mail: morsyleide.rosa@embrapa.br

F. K. Andrade · R. S. Vieira

Departamento de Engenharia Química, Universidade

Federal do Ceará (UFC), Fortaleza, CE, Brazil

J. P. S. Morais

Embrapa Algodão, Campina Grande, PB, Brazil

J. H. O. Nascimento

Departamento de Engenharia, Universidade Federal do

Rio Grande do Norte, Natal, RN, Brazil temperature of degradation along the several steps of $\mathrm{BC}$ deconstruction. Moreover, infrared analysis indicated that both processes led to an increase in the $\mathrm{I}_{\beta}$ content (43-66\%) of the fibers. Morphological analysis showed that the fibrillation process used exposed the internal faces of the ribbon-like nanofibrils, and thus, increased the surface area of the cellulose network, and produced fibers with a high aspect ratio (L/d). A thermally stable nanofibrillated suspension could be obtained by adding carboxymethyl cellulose as a simple and effective way to maintain cellulose fibers dispersed in the solution during sterilization by autoclaving.

F. M. P. Gama

IBB, Institute for Biotechnology and Bioengineering, University of Minho, Braga, Portugal 


\section{Graphical abstract}

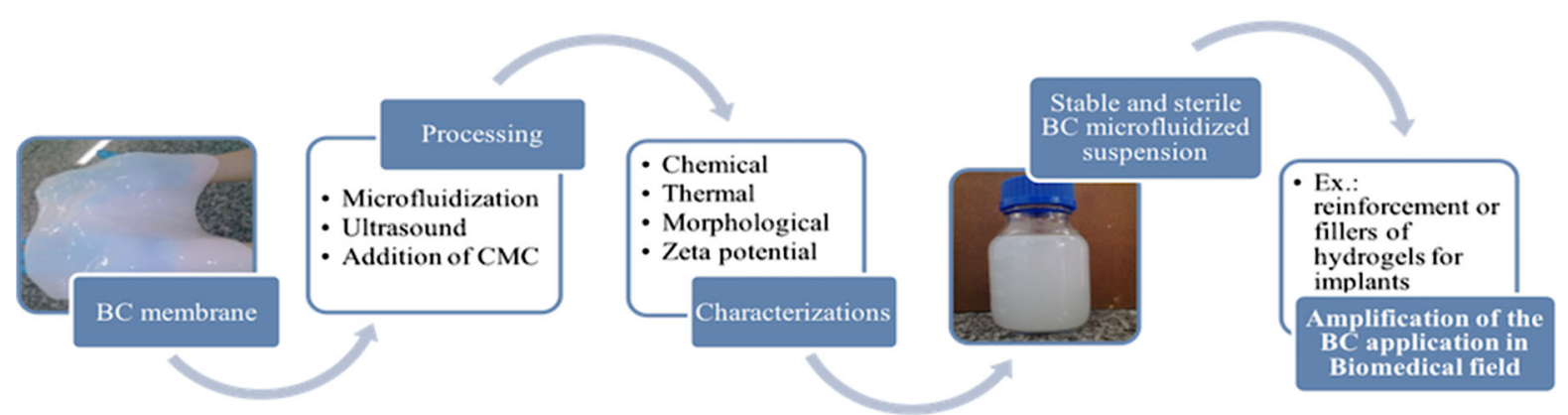

Keywords Bacterial cellulose $\cdot$ Nanofibrillated cellulose $\cdot$ Microfluidization $\cdot$ Sterilization

\section{Introduction}

Bacterial cellulose (BC) is an extracellular microbial product mainly produced by Komagataeibacter (formerly known as Gluconacetobacter) and is secreted into the aqueous culture medium directly in the form of nanofibers that form a pellicle in the culture medium. In contrast to other well-known types of cellulose, such as those from wood, BC is chemically pure, since it is free of lignin, pectin, hemicelluloses, and other biogenic compounds. In fact, depending on the plant source, the extraction process of cellulose may require corrosive chemicals that are hazardous to the environment, resulting in high economic, environmental, and social costs (Jonoobi et al. 2009; Gea et al. 2011; Vasconcelos et al. 2017).

$\mathrm{BC}$ could be produced in synthetic media containing mostly glucose and organic nitrogen (yeast extract and/or peptone). However, these pure nutritional components are costly and have limited BC production on an industrial scale. On the other hand, culture media composed of agroindustrial sources or waste add value to agroindustrial chains, favors the production of BC in a large scale at a low cost, besides are an alternative for the use of some wastes that are discarded in an inadequate way in the environment. The synthesis of $\mathrm{BC}$ from fruit juices, molasses, waste water of candied jujube-processing industry, food supply chain waste and agricultural by-products, mesquite extract, among others is well documented in the literature (Kurosumi et al. 2009; Çakar et al.
2014; Li et al. 2015; Molina-Ramírez et al. 2017; Nascimento et al. 2016).

One of the great fields of application of BC is the Biomedical area, for example as artificial vascular grafts, wound dressing, treating of damaged peripheral nerves, membranes in orthodontic treatment, cartilage replacement, matrix for drug delivery, in the composition of matrices used in bone repair (Sulaeva et al. 2015; Huang et al. 2014; Yin et al. 2015; Ullah et al. 2017). However, the use of $B C$ in the form of films or membranes, as it is produced by static culture fermentation, limits the application of this material. To overcome this limitation, it is possible to transform the $3 \mathrm{D}$ structure of the microfibril network in a stable suspension of nanofibrillated cellulose (NFC), thus, adding versatility and new features to this cellulosic material.

Over the years, the technology for the production of NFC has evolved. New sources of cellulose, new mechanical processes, and new pre- and post-treatments have been developed, with the aim of reducing energy consumption and producing new NFC-based materials on an industrial scale. Microfluidization exerts great shear stress on the fibers compared with other processes, and is capable of synthesizing highperformance nanofibrils (Qing et al. 2013). In this method, fibers pass through an intensifier pump that increases the output pressure, followed by passage through an interaction chamber, wherein the fibers are defibrillated by shear forces due to the collision against the walls of the channel at a constant shear rate. Moreover, the interaction chamber can be designed with different geometries to produce different sizedmaterials (Khalil et al. 2014).

An important issue for materials intended for biomedical applications is the obtainment of a sterile 
end product. In the case of $\mathrm{BC}$ membranes, this material generally is sterilized by autoclaving (pressured vapor sterilization) (Andrade et al. 2013), a method which is simple, economic, fast, nontoxic, and safe for the environment. However, in case of the suspension of nanofibrillated cellulose, steam sterilization can lead to particle aggregation. In fact, sterilization of NFC suspensions is scarcely reported in the literature, despite the essential importance of this step for the preparation of cellulose suspensions with application in the pharmaceutical or medical fields. In this context, the aims of this work was the production and characterization of a stable and sterile nanofibrillated cellulose suspension with potential for application in the biomedical field.

\section{Experimental procedures}

\section{Materials}

\section{Reagents and medium components}

Sodium dodecyl sulfate (SDS), sodium hydroxide, and low-viscosity (50-200 cps, $4 \%$ in $\mathrm{H}_{2} \mathrm{O}$ at $25{ }^{\circ} \mathrm{C}$, MW $90 \mathrm{kDa}$ ) carboxymethyl cellulose (product no. C5678) were purchased from Sigma-Aldrich (St. Louis, Missouri, US).

\section{Bacterial cellulose}

Bacterial cellulose was obtained from HTK Food Co., Ltd (Ho Chi Minh City, Vietnam). To remove possible microbial, protein, and lipid contamination, the raw material was first washed with $0.4 \% \mathrm{NaOH}$, and then, with distilled water until neutralization. After that, cellulose was immersed twice in 5\% SDS solution. Finally, the $\mathrm{BC}$ was washed with distilled water for the complete removal of SDS. After purification, the BC pellicles were autoclaved $\left(121^{\circ} \mathrm{C}, 15 \mathrm{~min}\right)$, and stored at $4{ }^{\circ} \mathrm{C}$ before use.

\section{Preparation of NFC suspensions}

First, the $\mathrm{BC}$ membranes were crushed using an ultraturrax (T50 Basic, IKA-Werke, Staufen, Germany) at $700 \mathrm{~W}$ for $10 \mathrm{~min}$, and subsequently lyophilized (L101, Liobras, SP, Brazil). After lyophilization, the $\mathrm{BC}$ was passed through an analytical mill (Ika-Werke, Staufen, Germany). Aqueous dispersions of cellulose $(0.85 \%, \mathrm{~m} / \mathrm{v})$ were prepared, and subsequently processed in a microfluidizer (M-110EH, Microfluidics, Westwood, MA, US). To obtain nanofibers with different characteristics, operating pressures between 20,000 and 25,000 psi, and chambers with openings of size 400,100, and 87 micrometers were sequentially used; 20 cycles were performed in each chamber (in order to assure the production of a homogenous suspension), and thus, 60 cycles were performed using the samples processed in the three microfluidizer chambers, while 20 and 40 cycles were performed using the samples processed in one and two chambers, respectively.

In the second step, sonication (Desruptor Unique, SP, Brazil) was carried out in an ice bath for $30 \mathrm{~min}$ or $60 \mathrm{~min}$ at $100 \mathrm{~W}$ with the more deconstructed fiber suspension (NFC-87), which was processed using the three chambers of the microfluidizer, in order to separate the nanofibril bundles through cavitation, and to assess the effect of ultrasonication on the fiber properties. Table 1 summarizes the different processing conditions tested, and the corresponding codes used throughout this paper.

Production of colloidal dispersions of CMC-NFC

Since we observed that autoclaving promotes the aggregation of the nanofibrillated cellulose dispersions, carboxymethyl cellulose (CMC) was used as a stabilizer. Three different concentrations of CMC $(0.2$, 0.5 , and $1.0 \%$ ) were added to the NFC-US60 formulation containing $2 \mathrm{mg} / \mathrm{mL}$ of nanofibrils. A pure $\mathrm{CMC}$ solution at $1 \%$ was used as the control. After the dissolution of CMC, the mixture was ultrasonicated (Desruptor Unique, SP, Brazil) in an ice bath for $10 \mathrm{~min}$ at $100 \mathrm{~W}$, and autoclaved at $121{ }^{\circ} \mathrm{C}$ for 15 min. Finally, the CMC-NFC dispersions obtained were characterized.

Characterization of the NFC colloidal dispersions

\section{Zeta potential}

The surface charge was estimated by analyzing the zeta potential of aliquots of the aqueous NFC suspensions using a Zetasizer NanoZS (Malvern Instruments, Worcs UK). Three measurements were performed for each suspension. 
Table 1 Processing methods for the production of nanofibrillated cellulose (NFC) from bacterial cellulose and NFC properties (crystallinity, crystallite size, infrared index data)

\begin{tabular}{|c|c|c|c|c|c|}
\hline $\begin{array}{l}\text { Experiment } \\
\text { code }\end{array}$ & Processing method/chamber size & $\begin{array}{l}\text { Crystallinity } \\
(\%)^{\mathrm{a}}\end{array}$ & $\begin{array}{l}\text { Crystallite size } \\
(\mathrm{nm})\end{array}$ & $\begin{array}{l}\text { Infrared ratio } a 1372 / \\
a 2900^{\mathrm{b}}\end{array}$ & $\begin{array}{l}\text { MBHS } \mathrm{A}_{\mathrm{OH}} / \\
\mathrm{A}_{\mathrm{CH}}^{\mathrm{c}}\end{array}$ \\
\hline Pellicle & & $86 \pm 0.33$ & $5.8 \pm 0.16$ & 0.92 & 2.13 \\
\hline NFC-UT & UT & $80 \pm 0.15$ & $5.7 \pm 0.07$ & 0.87 & 4.42 \\
\hline NFC-400 & $\mathrm{UT}+\mathrm{MFD}(400 \mu \mathrm{m})$ & - & - & 0.68 & 4.65 \\
\hline NFC-100 & $\mathrm{UT}+\mathrm{MFD}(400$ and $100 \mu \mathrm{m})$ & $73 \pm 2.10$ & $4.6 \pm 0.25$ & - & - \\
\hline NFC-87 & $\mathrm{UT}+\operatorname{MFD}(400,100$, and $87 \mu \mathrm{m})$ & $75 \pm 0.46$ & $4.4 \pm 0.1$ & - & - \\
\hline NFC-US30 & $\begin{array}{c}\mathrm{UT}+\mathrm{MFD}(400,100 \text { and } \\
87 \mu \mathrm{m})+\mathrm{US}(30 \mathrm{~min})\end{array}$ & $74 \pm 0.19$ & $4.2 \pm 0.08$ & 0.61 & 6.88 \\
\hline NFC-US60 & $\begin{array}{c}\mathrm{UT}+\mathrm{MFD}(400,100 \text { and } \\
87 \mu \mathrm{m})+\mathrm{US}(60 \mathrm{~min})\end{array}$ & $65 \pm 0.41$ & $4.0 \pm 0.05$ & 0.50 & 6.97 \\
\hline
\end{tabular}

UT, ultraturrax; MFD, microfluidization; US, ultrasonication; Chamber size used (400 $\mu \mathrm{m}, 100 \mu \mathrm{m}$, and $87 \mu \mathrm{m}) ;-$, not determined

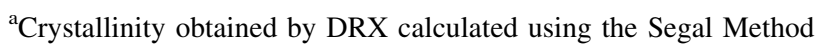

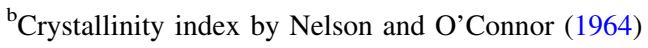

${ }^{\mathrm{c}}$ Mean strength of the hydrogen bond

\section{FTIR studies}

The vibrational spectra were obtained using a spectrophotometer (Agilent Cary 660 FTIR spectrometer, Santa Clara, CA, US). Samples were ground and pelletized using $\operatorname{KBr}(1: 10$, w/w), and subjected to uniaxial pressure. Spectra were obtained between 4000 and $400 \mathrm{~cm}^{-1}$ at a resolution of $4 \mathrm{~cm}^{-1}$ over 100 scans. The comparative crystallinity of cellulose samples was measured through the ratio of peak heights at 1372 and $2900 \mathrm{~cm}^{-1}$ (Nelson and O'Connor 1964). The mean strength of the hydrogen bond (MHBS) was calculated according to Levdik et al. (1967) as the ratio of $\mathrm{A}_{\mathrm{OH}} / \mathrm{A}_{\mathrm{CH}}$, where $\mathrm{A}$ is the integral intensity of the stretching vibration bands of the subscript group.

\section{$\% I_{\beta}$ determination}

In the FTIR spectra of cellulose, hydrogen-bonding vibrational bands are present in the $700-800 \mathrm{~cm}^{-1}$ range (Szymańska-Chargot et al. 2011). The bands at 750 and $710 \mathrm{~cm}^{-1}$ are characteristic of $\mathrm{I}_{\alpha}$ and $\mathrm{I}_{\beta}$ allomorphs, respectively, and they have been used for the estimation of the ratio of these cellulose dimorphs obtained from various organisms (Pecoraro et al. 2008). For all spectra, a Gaussian function was fitted under the peaks around 750 and $710 \mathrm{~cm}^{-1}$, and then, the area under the peaks was calculated. The percentage of the $\mathrm{I}_{\beta}$ form in the fibers was calculated by using the following equation (Szymańska-Chargot et al. 2011):

$\% \mathrm{I}_{\beta}=\mathrm{A}_{710} /\left(\mathrm{A}_{710}+\mathrm{A}_{750}\right) \times 100$

where $A_{710}$ and $A_{750}$ correspond to the areas of the bands around 710 and $750 \mathrm{~cm}^{-1}$. Baseline corrections were performed using MagicPlot Student 2.5.1 Software.

\section{XRD studies}

X-ray diffraction analyses of the fibers were performed on an X-ray diffractometer (Rigaku DMaxB, Tokyo, Japan), using $\mathrm{Cu} \mathrm{K} \alpha$ radiation. The diffraction data were collected between $10^{\circ}$ and $50^{\circ}$ ( $2 \theta$ values) at a scanning speed of $0.5^{\circ} \mathrm{min}^{-1}$. The crystalline index (CI) was determined using the method described by Segal et al. (1959).

The cellulose crystallite size was calculated from the width of the peak at $2 \theta$ around $22.4^{\circ}$ by means of the Scherrer equation (Vanhatalo et al. 2016):

$\mathrm{CS}=\mathrm{k} \cdot \lambda / \beta \cdot \cos \theta$ 
where CS is the size of the crystallite, $\mathrm{k}$ is the Scherrer constant (0.94), $\lambda$ is X-ray wavelength, $\beta$ is the full width at half maximum in radians, and $\theta$ is the Bragg angle.

\section{Thermogravimetric analysis (TGA)}

The thermal stability of the NFCs was assessed by using a thermogravimetric analyzer (Model STA 6000, Perkin Elmer; Shelton, USA). Dried samples (2.5-6.7 $\mathrm{mg}$ ) were heated in the temperature range of $30-700{ }^{\circ} \mathrm{C}$ in a nitrogen atmosphere $(40 \mathrm{~mL} / \mathrm{min})$ at a heating rate of $20{ }^{\circ} \mathrm{C} \mathrm{min}^{-1}$. The activation energy of the decomposition of the samples was obtained by heat flow mode, under the same thermogravimetric analysis conditions. The curve from the empty porcelain pan was used as reference for the baseline. The amount of energy in decomposition reaction (E) of the samples was calculated as the integral of peak areas using Start Pyris software.

\section{Scanning electron microscopy (SEM)}

Lyophilized NFCs were mounted on stubs with conductive carbon tape, and sputter-coated with platinum. The images of the prepared samples were taken by using a scanning electron microscope (Zeiss DMS-940, SP, Brazil) at a working distance of $13 \mathrm{~mm}$ and accelerating voltage of $15 \mathrm{kV}$. The widths of the freeze-dried fibers were measured from 50 individual fibers.

\section{Transmission electron microscopy (TEM)}

A drop of the NFC or NFC-CMC suspension was placed on a 300-mesh copper grid. After $10 \mathrm{~min}$, excess of the sample was removed carefully using a filter paper. Following this, one drop of $1 \%$ phosphotungstic acid solution (w/v) was added, and the excess was removed using filter paper after $30 \mathrm{~s}$. The samples were then placed in a desiccator for $24 \mathrm{~h}$, and then, analyzed using FEG-SEM Mira3-LM (TESCAN, SP, Brazil) equipped with a scanning transmission electron microscopy detector (STEM) with a magnification of up to $1,000,000 \times$.

\section{Results and discussion}

NFC characterization

\section{Zeta potential}

The results of the zeta potential analysis showed that the zeta potential of bacterial cellulose (NFC-UT) was negative with a module of about $28 \mathrm{mV}$ (Table 1) prior to microfluidization. It is noteworthy that a zeta potential of about $30 \mathrm{mV}$ is needed for good colloidal stability (Mirhosseini et al. 2008); therefore, the nanofibrils tend to aggregate when stored for a long period of time.

The results also showed that the zeta potential appeared to decrease with decrease in the length of the fibers, as the $\mathrm{BC}$ was subjected to microfluidization and ultrasonication (Table 1). Similar to our results, Tonoli et al. (2012) observed that the stability of cellulose micro/nanofiber suspensions from Eucalyptus kraft pulp was compromised, since the value of the zeta potential changed from - $49.8 \mathrm{mV}$ (of the "onlymilled" fibers) to $-19.1 \mathrm{mV}$ after sonication. In the work reported by Tsalagkas et al. (2015), the exposure of a BC suspension to ultrasonication yielded a drop in the zeta potential from -35.9 to $-21.8 \mathrm{mV}$. Analyzing our results together with those of other authors, there appears to be a tendency in the decrease of the zeta potential to close to neutrality when cellulose fibers are treated with mechanical process. It's a possibility that when fibers are exposed a long time to changes in the $\mathrm{pH}$ of the aqueous medium, due to the presence of the dissolved $\mathrm{CO}_{2}$, the zeta potential of the fibers become more negative, while the newly exposed faces of the fibers are more neutral as would be expected for pure cellulose. However, a more in-depth study is needed to understand this phenomenon.

\section{$X$-ray diffraction studies}

Microfluidization and ultrasonication had impacted on the structure of crystalline cellulose, as revealed by the CI values and crystallite sizes (CS) (Fig. 1, Table 1). The mechanical process had decreased the NFC crystallinity from 86 to $74 \%$, and 60 min of ultrasonication had further decreased this value to $65 \%$. It is noteworthy that the crystallinity is direct related to the tensile strength and rigidity of cellulose fibers due to the greatly ordered and compact molecular structure 


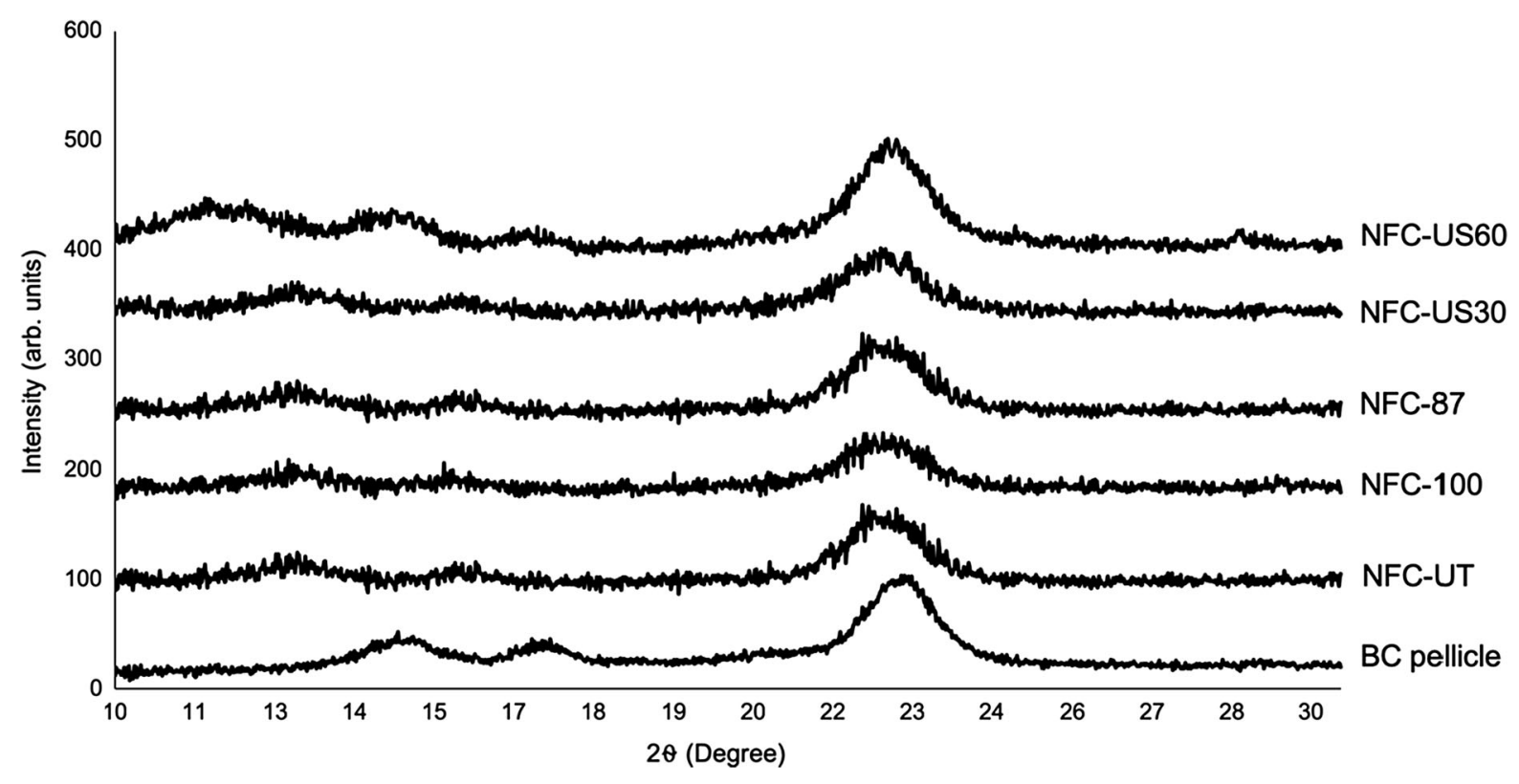

Fig. 1 XRD pattern of $\mathrm{BC}$ pellicle and the nanofibrillated cellulose fibers

among cellulose molecules (Li et al. 2014; Sakurada et al. 1962), this way the reduction of the CI during microfluidization may be explained to the fact that during this process, the cellulose fibers collides under very high pressure $(25,000 \mathrm{psi})$ against the walls of the chambers, which preferentially break the fibers in their crystalline regions, given their higher rigidity in structure than the amorphous regions.

A reduction in the CS of the NFCs by $24 \%$ $(5.8-4.4 \mathrm{~nm})$ was observed with decrease in the size of the chamber openings (as well as increase in the number of cycles); decreases in the CS of the NFCs by $27.6 \%$ and $31 \%$ after $30 \mathrm{~min}$ and $60 \mathrm{~min}$ of ultrasonication were also observed, respectively (Table 1).

The reduction in cellulose crystallinity during cavitation could be explained by the hot-spot theory proposed by Noltingk and Neppiras (1950). The cavitation phenomenon (sequential formation, growth, and collapse of many microscopic vapor bubbles in a liquid), which is produced by ultrasonication creates highly localized hot spots. These transient, localized hot spots in cold liquids drive high-energy chemical reactions that occur at temperatures of ca $5000{ }^{\circ} \mathrm{C}$, pressures of about $1000 \mathrm{~atm}$, and heating and cooling rates above $10^{10} \mathrm{~K} / \mathrm{s}$. These high cooling rates in the hot spots interfere with the reorganization and crystallization of cellulosic material, and transform the crystalline region into amorphous region, resulting in lowered crystallinity.

It is known that the crystallographic properties of reinforcing materials may influence the mechanical and thermal performance of a composite material. In the case of celluloses, higher crystallinity is related to greater mechanical strength and higher thermal stability (Dufresne 2012). Therefore, for the biomedical applications of composite materials, a filler with moderate mechanical resistance may be required, though other factors (such as composition of the matrix, concentration of the reinforcement, interfacial adhesion between the matrix and the fibers and so on) affect the mechanical performance of the final product (Ku et al. 2011). In any case, it seems possible to modulate these properties according to the method used to deconstruct the $\mathrm{BC}$ structure.

\section{FTIR studies}

To evaluate the effects of microfluidization and ultrasonication on the chemical structure of $\mathrm{BC}$, especially the $I_{\beta}$ content, infrared analyses were performed. In this case, only fibers at very distinct stages of the deconstruction process (namely, BC pellicle, NFC-400, NFC-US30, and NFC-US60) were analyzed. 


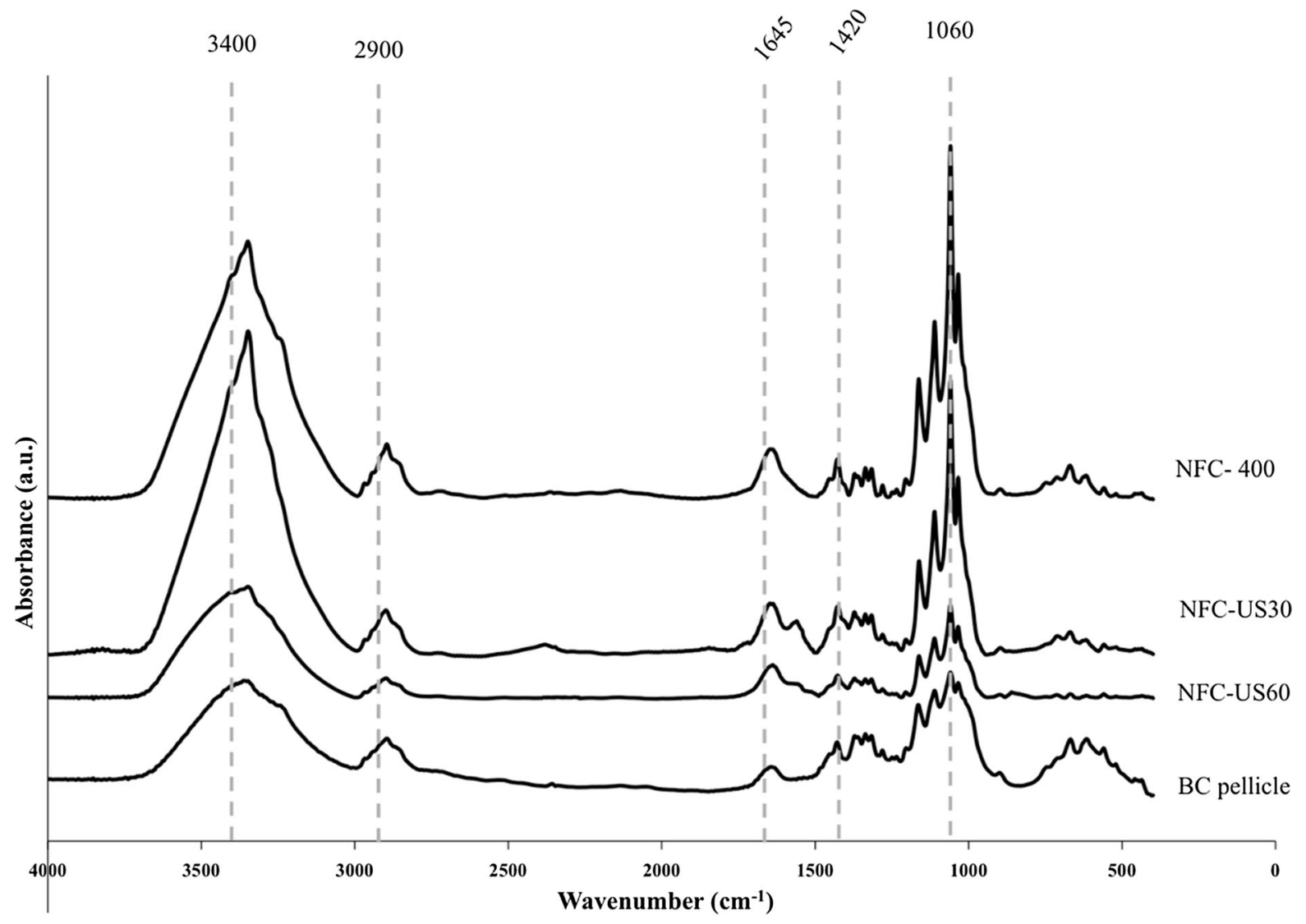

Fig. 2 FTIR spectra of the BC pellicle and the BC suspensions

Figure 2 shows the typical infrared (IR) spectrum of NFCs. The broad absorption bands at $3500-3200 \mathrm{~cm}^{-1}$ were attributed to the stretching frequency of the $-\mathrm{OH}$ group as well as to the intramolecular and intermolecular hydrogen bonds. The band around $2900 \mathrm{~cm}^{-1}$ was due to $\mathrm{C}-\mathrm{H}$ stretching and $-\mathrm{CH}_{2}$ asymmetric stretching vibrations. The band at $1645 \mathrm{~cm}^{-1}$ was due to the bending mode of the absorbed water. The bands around 1420 and $1320 \mathrm{~cm}^{-1}$ were attributed to $-\mathrm{CH}_{2}$ scissoring and $\mathrm{OH}$ bending vibration, respectively. The band at $1060 \mathrm{~cm}^{-1}$ was due to $\mathrm{OCH}-\mathrm{O}-\mathrm{CH}_{2}$ stretching (Vasconcelos et al. 2017). The results presented in Table 1 showed that the crystalline index obtained through FTIR analysis using the method proposed by Nelson and O'Connor (1964) were in agreement with the XRD results. From the FTIR results is also possible to observe that the mean strength of the hydrogen bond (MBHS) increase along with the deconstruction process, which indicates that weaker hydrogens bonds were cracked during these processes and the contribution of strong hydrogen bonds to the mean values increased.

Cellulose has several polymorphs, however, only cellulose I is found in nature. This native cellulose is in turn, composed of two crystalline phases $\left(\mathrm{I}_{\alpha}\right.$ and $\left.\mathrm{I}_{\beta}\right)$. The proportion of $I_{\alpha}$ and $I_{\beta}$ varies, depending on the source of the cellulose. Generally, cell walls of higher plants abound in cellulose $I_{\beta}$, whereas celluloses found in algal cell walls or produced by some bacterial species are rich in the $I_{\alpha}$ allomorph (Dufresne 2012).

Figure 3 shows the FTIR spectra of the BC pellicle and the NFC suspensions in the region between $800 \mathrm{~cm}^{-1}$ and $650 \mathrm{~cm}^{-1}$. The FTIR spectra indicate that the ratio of cellulose $I_{\alpha}$ to total crystal phases in the nanocellulose had decreased after both microfluidization and ultrasonication, and in the latter case, for only up to $30 \mathrm{~min}$.

Similar results were obtained when another mechanical process (aqueous counter collision) was 

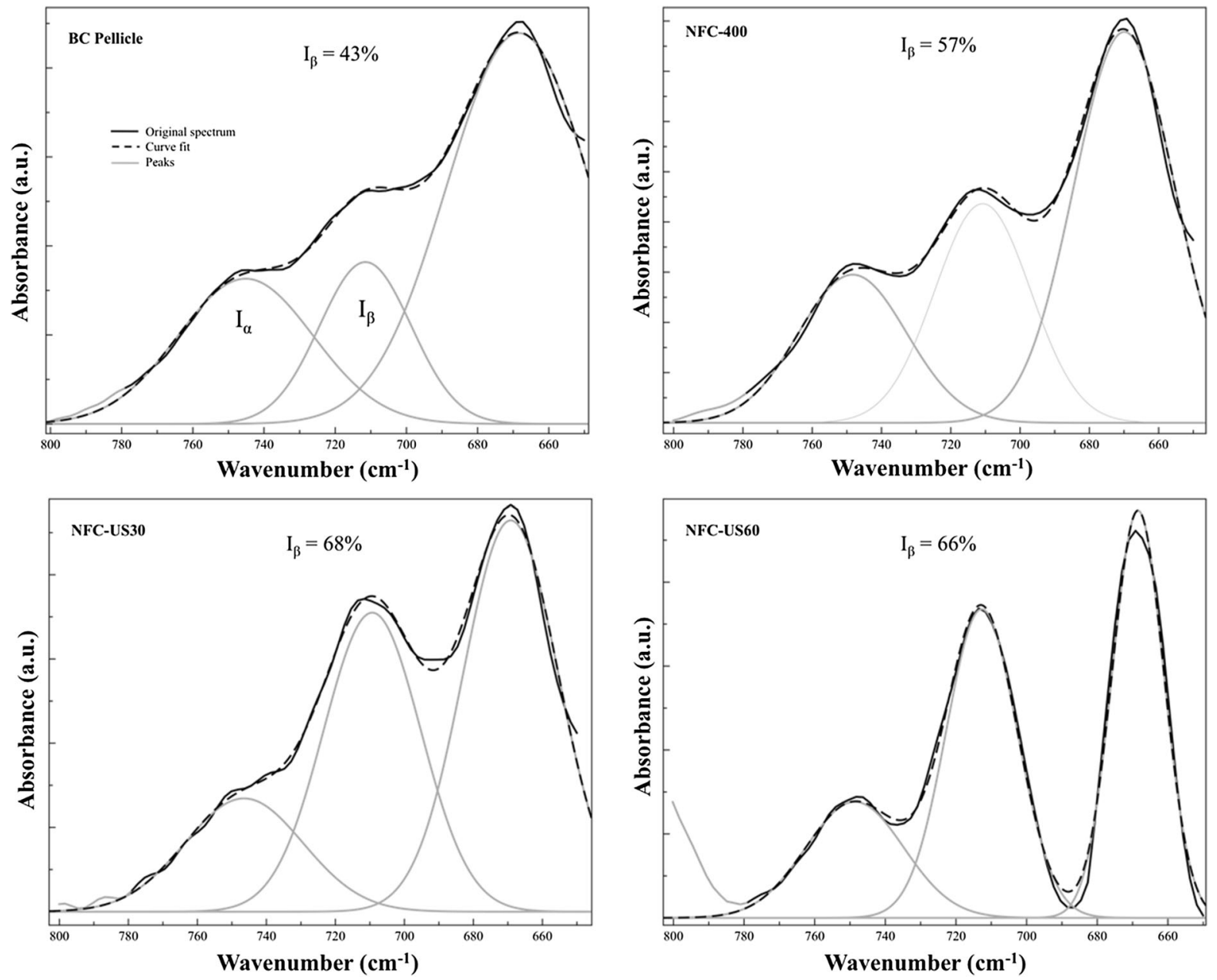

Fig. 3 FTIR spectra of the BC pellicle and the NFC suspensions in the region between $800 \mathrm{~cm}^{-1}$ and $650 \mathrm{~cm}^{-1}$. The deconvoluted absorption peaks were attributed to the $\mathrm{I}_{\alpha}\left(750 \mathrm{~cm}^{-1}\right)$ and $\mathrm{I}_{\beta}\left(719 \mathrm{~cm}^{-1}\right)$ crystalline forms of cellulose

applied to produce microfibrillated cellulose (Kose et al. 2011) or when Briois et al. (2013) studied the effect of low-frequency sonication on cellulose microfibrils obtained from the microalga, Glaucocystis nostochinearum (also rich in the $\mathrm{I}_{\alpha}$ allomorph). The fibrillation was accompanied by a change in the proportion of the two allomorphs; at the same time that the $I_{\alpha}$ phase decreased from $90 \%$ to only $36 \%$, the $I_{\beta}$ component increased from 10 to $64 \%$, and moreover, crystallinity had decreased from 72 to $60 \%$.

As mentioned previously, the cavitation phenomenon produced by ultrasonication creates localized hot spots (Noltingk and Neppiras 1950). Therefore, we hypothesized that the high localized temperature/pressure attained by cavitation, which is higher than the cracking temperature of intermolecular hydrogen bonds in cellulose $\mathrm{I}_{\alpha}\left(200{ }^{\circ} \mathrm{C}\right.$ ) (Wada et al. 2003) and cellulose $I_{\beta}\left(230{ }^{\circ} \mathrm{C}\right)$ (Wada et al. 2010) induced the thermal expansion of the crystal lattice with the formation of a "high temperature intermediate" structure (Wang et al. 2015). During the cooling process, the barrier to the formation of $I_{\beta}$ is much smaller than that to the formation of $\mathrm{I}_{\alpha}$, and hence, kinetics favor the formation of $\mathrm{I}_{\beta}$ (Matthews et al. 2012), resulting in the transformation from the $I_{\alpha}$ phase to the $\mathrm{I}_{\beta}$ phase.

The transformation from the $\mathrm{I}_{\alpha}$ phase to the $\mathrm{I}_{\beta}$ phase proceeds from the surface to the interior of large microfibrils, and thus, reaching the outermost region of the cellulose bundles first (Matthews et al. 2012). The fact that the percentage of $I_{\beta}$ does not vary considerably after the initial 30 -min ultrasonication is 
probably since, at this point, some of the crystalline domains are destroyed because of prolonged cavitation and converted to amorphous cellulose at the same time that the $I_{\alpha}$ phase is transformed to the $I_{\beta}$ phase. As a matter of fact, the CI had decreased substantially from 30 to $60 \mathrm{~min}$ of ultrasonication (as described in the section on the results of the XRD analysis).

\section{$T G A$}

Lyophilized NFCs exhibited three main thermal events similar to those described in others reports on BC (Vasconcelos et al. 2017). The first one occurred at approximately $30-100{ }^{\circ} \mathrm{C}$, and was due to the presence of a small amount of moisture. The second event-characterized by a sudden loss in weight within a small temperature range-started at approximately $280-340{ }^{\circ} \mathrm{C}\left(\mathrm{T}_{\text {Onset }}\right)$ and continued to $400{ }^{\circ} \mathrm{C}$ and was related to cellulose degradation (dehydration, decomposition, and depolymerization of the glycoside units). The third thermal event, which

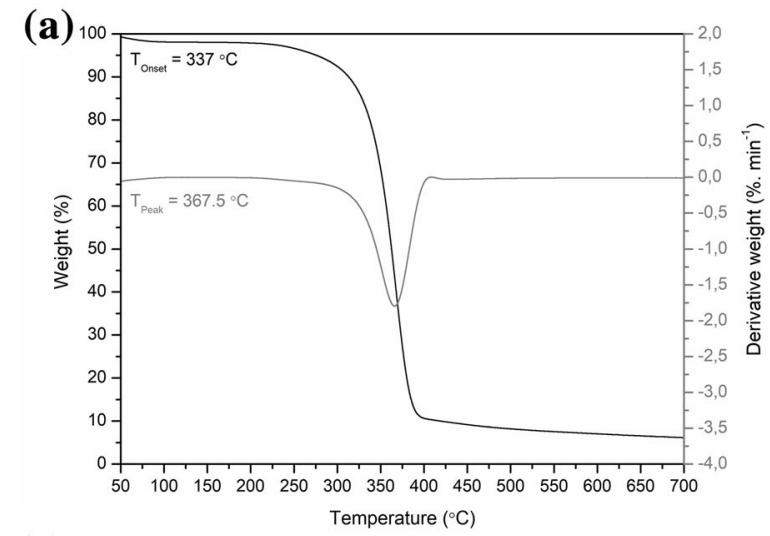

$$
\text { (c) }
$$

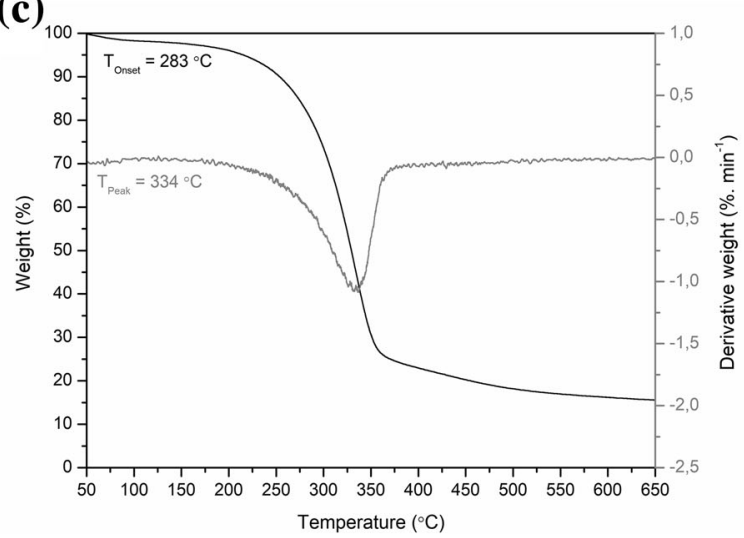

continued over a range of $400-650{ }^{\circ} \mathrm{C}$ was related to the oxidation and breakdown of carbonaceous residues (Fig. 4).

Table 2 summarizes the initial degradation temperature, maximum weight loss temperature and the enthalpy variation of the degradation reaction of the main degradation stage of BC pellicle and NFCs suspensions. The maximum weight loss temperature was the temperature at which the derivative of the TG curve reached a maximum.

The onset temperature of thermal degradation of NFCs varied from 282 to $323{ }^{\circ} \mathrm{C}$ while the DTG peak varied from 334 to $367.5^{\circ} \mathrm{C}$ (Fig. 4, Table 2). It is noteworthy that the onset degradation temperature as well as the DTG peak had decreased as the BC pellicle was deconstructed by microfluidization and ultrasonication. The results of the TGA are in agreement with those of the XRD analysis, since it is well reported in the literature that a decrease in crystallinity leads to a decrease in the thermal stability of cellulose (Dufresne 2012).
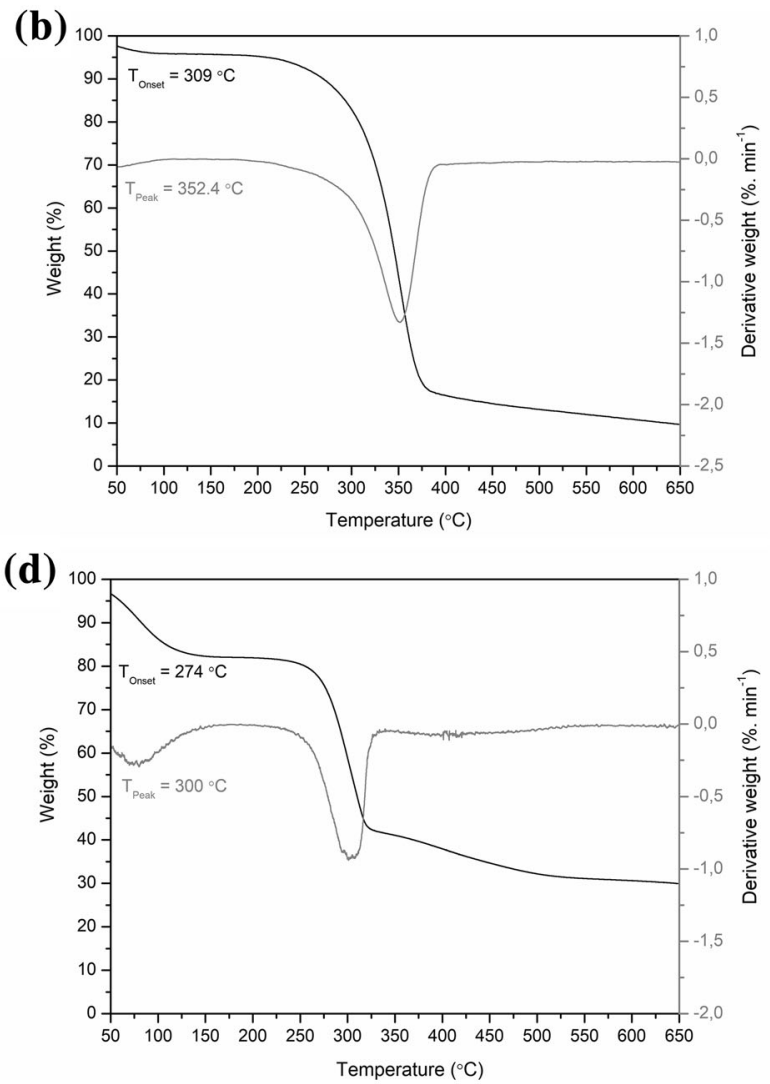

Fig. 4 TGA and DTG curves of a BC pellicle, b NFC-87, c NFC-US60 and d NFC10 samples 
Table 2 Thermal properties of bacterial cellulose and NFCs (onset degradation temperature, DTG peak maximum, activation energy of degradation)

activation energy of the degradation reaction

\begin{tabular}{lllc}
\hline Experiment code & 2nd event $\mathrm{T}_{\text {Onset }}\left({ }^{\circ} \mathrm{C}\right)$ & DTG peak $\left({ }^{\circ} \mathrm{C}\right)$ & $\mathrm{E}(\mathrm{J} / \mathrm{g})^{\mathrm{a}}$ \\
\hline Pellicle & 337 & 367.5 & 112.9 \\
NFC-UT & 321 & 359 & 110.2 \\
NFC-400 & 316 & 356 & 241.1 \\
NFC-100 & 317 & 355 & 345.7 \\
NFC-87 & 309 & 352.4 & 461.85 \\
NFC-US30 & 294 & 338.4 & 145.5 \\
NFC-US60 & 283 & 334 & 66.7 \\
\hline
\end{tabular}

Even though there was a reduction in the thermal stability of $28{ }^{\circ} \mathrm{C}$ and $54{ }^{\circ} \mathrm{C}$ after microfluidization and ultrasonication, respectively, this reduction does not compromise the use of NFCs as reinforcements for implantable devices; this is because, the material would be exposed to the sterilization temperature ( $121{ }^{\circ} \mathrm{C}$ by autoclaving), as well as the body temperature, which is well below the thermal degradation value of cellulose.

Analyzing the results from the activation energy of the degradation reaction $(\mathrm{E})$, there was no difference between the values from BC pellicle and the NFC-UT, since the ultraturrax process promote a mild physic effect on the cellulose fibers. On the other hand, an increase is observed for the NFC-400, NFC-100 and NFC-87. As already said during the microfluidization process weaker hydrogens bonds were cracked and the contribution of strong hydrogen bonds to stabilize the structure increased. Thus, during the thermal degradation more energy is necessary to broke down the polymer backbone. However, the contrary effect is observed for both NFC-US30 and NFC-US60. In this case, probably both the crystalline degree and crystallite size affected the activation energy, in which is the lower the CI and CS the lower is the activation energy.

\section{Morphological studies}

Scanning and transmission electron microscopic images were taken in order to examine the structural differences among the nanofibrillated cellulose samples. The SEM images can be accessed in the Online Resource of this article.

Owing to the self-aggregation, bundling, and overlapping of individual NFCs during sample preparation for observation by STEM, the accurate measurement of dimensions was difficult. For this reason, the dimensions of only well-dispersed nanocellulose fibers were measured using a FEG-SEM with a STEM detector.

The resulting materials were nanofibrils with an average width of $30 \pm 7 \mathrm{~nm}$ (Fig. 5b), while the average width of the nanofibers of the intact pellicle was $71 \pm 16 \mathrm{~nm}$ (Fig. 5a), which shows that the fibrillation process exposed the internal faces of the ribbon-like nanofibrils, and thereby, increased the surface area of the cellulose network. The average length (L) of the fibers produced in this work was too long or the ends of the individual fibers could not be clearly identified for accurate measurement by electron microscopy. Thus, by microfluidization, it was possible to separate the fibers in the complex 3D network of $\mathrm{BC}$ pellicles into a suspension of individual nanofibers with a high aspect ratio (L/d).

\section{Characterization of NFC-CMC suspension}

It is known that bacterial cellulose pellicles are stable after autoclaving (Andrade et al. 2013), and therefore, this sterilization method was utilized to obtain a sterile suspension of cellulose nanofibers that could be of use in the biomedical field. However, the dispersion showed poor colloidal stability, and the nanofibrils aggregated immediately after sterilization. In a way, this was an expected outcome, since NFC suspensions possess a zeta potential module under $30 \mathrm{mV}$.

The colloidal stability and dispersion of cellulose fibers can be enhanced in different ways, such as by using molecules or polymers that interact with the colloidal particles. Carboxymethyl cellulose (CMC) is frequently used to disperse fibers, since it reduces flocculation because of its ability to reduce fiber-tofiber friction (Liimatainen et al. 2009). CMC is a water-soluble, linear, anionic polysaccharide derived 

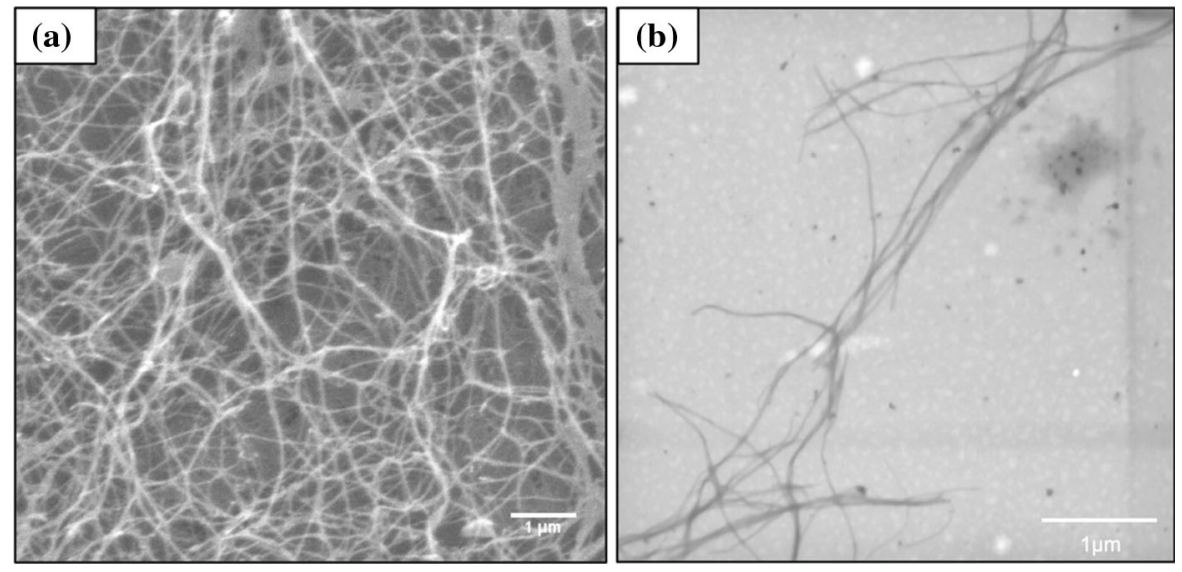

Fig. 5 SEM micrograph of the BC pellicle (a), TEM image of the NFC solution taken using a FEG-SEM equipped with a scanning transmission electron microscopy detector (STEM) (b)

from cellulose, which is composed of $\beta$-(1,4)-linked d-glucopyranose chains, and is characterized by its high viscosity, non-toxicity, non-allergenicity, and biodegradability, as well as low production cost (Jinshu 2014; Ramli and Wong 2011). An obvious advantage of utilizing CMC to increase charge is that the sorption of this macromolecule yields a high surface charge without adversely affecting the fiber properties.

To evaluate the effect of CMC on the stability of the nanofibril suspension after autoclaving, $0.2,0.5$ or $1.0 \% \mathrm{CMC}$ was added to the NFC-US60 solutions. The CMC used in this work was of low viscosity (50-200 cps, $4 \%$ in $\mathrm{H}_{2} \mathrm{O}$ at $25^{\circ} \mathrm{C}$ ) as indicated by the manufacturer, and is less affected by autoclaving than $\mathrm{CMC}$ of medium and high viscosity.
The results of the zeta potential analysis of the NFC-CMC solutions showed (Table 3) that the modules increased to values ranging from 55 to $60 \mathrm{mV}$. After autoclaving at $121{ }^{\circ} \mathrm{C}$ for $20 \mathrm{~min}$, no aggregate was observed in the NFC-CMC solutions. Moreover, after centrifugation at $2000 \mathrm{rpm}$ during $20 \mathrm{~min}$ the NFC-US60 fibers precipitate while the NFC-CMC fibers remained in suspension (Fig. 6a, b, respectively). In an additional step, the NFC-CMC was lyophilized, then resuspended in distilled water and ultrasonicated $(100 \mathrm{~W} ; 5 \mathrm{~min})$, followed by a centrifugation at $2000 \mathrm{rpm}$ during $20 \mathrm{~min}$. As can be se in Fig. 6c, the NFC-CMC fibers were completely resuspended and sowed to be a stable colloidal solution.

The IR spectra (see Online Resource) of all the samples containing CMC show the typical absorption

Table 3 Properties (onset degradation temperature, DTG peak maximum and zeta potential) of the CMC-NFC suspension

\begin{tabular}{|c|c|c|c|c|c|c|c|c|}
\hline \multirow{2}{*}{$\begin{array}{l}\text { Experiment } \\
\text { code }\end{array}$} & \multirow[t]{2}{*}{ Composition } & \multicolumn{2}{|c|}{$\mathrm{T}_{\text {onset }}\left({ }^{\circ} \mathrm{C}\right)$} & \multicolumn{2}{|c|}{ DTG peak $\left({ }^{\circ} \mathrm{C}\right)$} & \multicolumn{2}{|l|}{$\mathrm{E}(\mathrm{J} / \mathrm{g})^{\mathrm{a}}$} & \multirow{2}{*}{$\begin{array}{l}\text { Zeta potential } \\
(\mathrm{mV})\end{array}$} \\
\hline & & $\begin{array}{l}\text { 1st } \\
\text { event }\end{array}$ & $\begin{array}{l}\text { 2nd } \\
\text { event }\end{array}$ & $\begin{array}{l}1 \text { st } \\
\text { event }\end{array}$ & $\begin{array}{l}\text { 2nd } \\
\text { event }\end{array}$ & $\begin{array}{l}1 \text { st } \\
\text { event }\end{array}$ & $\begin{array}{l}\text { 2nd } \\
\text { event }\end{array}$ & \\
\hline $\mathrm{CMC}$ & CMC $1.0 \%$ & 268 & 50 & 295 & 73 & 35.6 & 123.6 & $-62.5 \pm 3.5$ \\
\hline $\mathrm{NFC02}$ & $\begin{array}{l}\text { NFC-US60 + CMC } \\
0.2 \%\end{array}$ & 273 & 46 & 308 & 66 & 59.75 & 115.6 & $-57.2 \pm 1.6$ \\
\hline NFC05 & $\begin{array}{l}\text { NFC-US60 + CMC } \\
0.5 \%\end{array}$ & 275 & 44.5 & 305 & 65 & 111 & 130 & $-55.5 \pm 1.9$ \\
\hline NFC10 & $\begin{array}{l}\text { NFC-US60 + CMC } \\
1.0 \%\end{array}$ & 274 & 53 & 300 & 81 & 221.75 & 327.9 & $-60.1 \pm 0.5$ \\
\hline
\end{tabular}

CMC carboxymethyl celulose

${ }^{a}$ Activation energy of the degradation reaction 


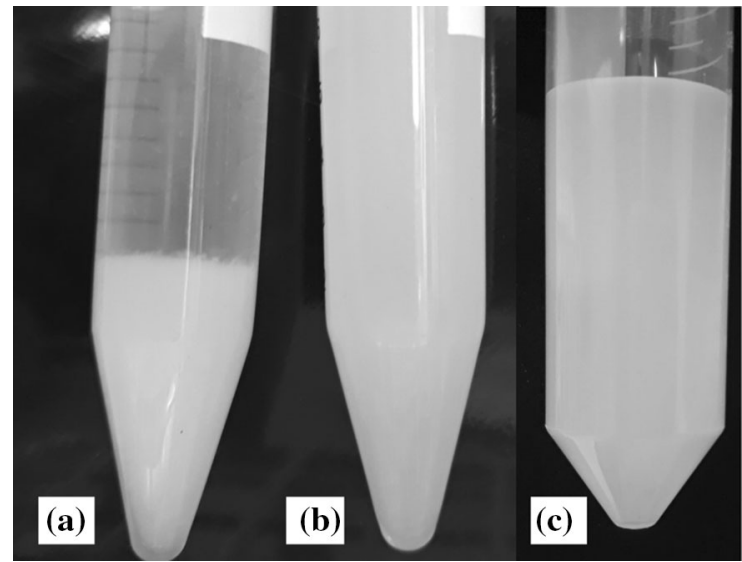

Fig. 6 Microfluidized BC suspension after centrifugation at $2000 \mathrm{rpm}$ and $20 \mathrm{~min}$. a NFC-US60 and b, c NFC-CMC. c The suspension was lyophilized and resuspended before being centrifuged

of the cellulose backbone as well as the presence of the carboxymethyl ether group at $1590 \mathrm{~cm}^{-1}$ (Chai and Isa 2013).

The TGA analysis revealed that CMC had greater loss in weight than cellulose in the first stage, as a consequence of the highly hydrophilic nature of the carboxyl group. CMC initiated the process at lower temperatures compared to cellulose because of possible decomposition through decarboxylation. According to Basta et al. (2016) and Yadollahi and Namazi (2013) the presence of a second peak between 250 and $400{ }^{\circ} \mathrm{C}$ may be related to the decarboxylation and decomposition of cellulose, and the occurrence of a third-stage peak above $700{ }^{\circ} \mathrm{C}$ is related to the rapid volatilization and oxidation of char and formation of $\mathrm{Na}_{2} \mathrm{CO}_{3}$. Table 3 shows that the onset temperature of the 2nd event (the thermal degradation of cellulose) was $268{ }^{\circ} \mathrm{C}$ for $\mathrm{CMC}$, which thus, agrees with the data found in the literature (Basta et al. 2016; Yadollahi and Namazi 2013). The values of $\mathrm{T}_{\text {onset }}$ of the CMCcontaining NFC suspension were low $\left(273-275^{\circ} \mathrm{C}\right)$ when compared to that of pure NFC-US60 $\left(283{ }^{\circ} \mathrm{C}\right)$ and slightly higher than that of $\mathrm{CMC}\left(268{ }^{\circ} \mathrm{C}\right)$ and demonstrate the contribution of both the bacterial cellulose fibers and carboxymethyl cellulose components in the thermal properties of CMC-containing NFC suspension. The activation energy required in the degradation reaction is lower in $\mathrm{CMC}$, however the presence of CMC in NFC suspensions increase $E$, showing that the number of interaction forces between the cellulose fibers increase with the presence of CMC and more energy is necessary to broke down the polymer backbone.

When the NFC-CMC solution was analyzed by using SEM (See Online Resource), the spaces between the nanocellulose fibers seemed to be completely filled with CMC. The STEM analyses showed that the nanofibers dispersed in CMC exhibited a width of $40 \pm 4 \mathrm{~nm}$, a value which was slightly high when compared to the width of the nanofibers from the pure NFC solution, however, this difference was not significant. Possibly, the presence of surface charge generated by CMC had led to a slight swelling of the fibers. Although the mechanism underlying the nonionic attachment of CMC, which is a polyelectrolyte, to cellulose fibers is not completely clear, it was proposed that CMC acts as a "bifunctional" material with charged and uncharged segments that increase the tendency for cooperative hydrogen bonding between the free cellulose segments on the CMC backbone and the surface of the cellulose fibers. Thus, CMC modifies the surface by strong adsorption, and it increases the charge density of fibers (Kargl et al. 2012; Zemljič et al. 2006).

The results of the characterization of the CMCNFC suspensions showed that the addition of CMC had slightly decreased the thermal stability of the fiber suspension, however, even at its low concentration that was tested $(0.2 \%)$, CMC was capable of stabilizing the dispersibility of NFCs after autoclaving.

\section{Conclusions}

By microfluidization and ultrasonication, it was possible to separate fibers from the complex 3D network of $\mathrm{BC}$ pellicles into a suspension of individual nanofibers with a high aspect ratio (L/d). Both processes generate morphological changes leading to the reduction in the crystallinity and crystal size, which was accompanied by a partial allomorphic change from $\mathrm{I}_{\alpha}$ to $\mathrm{I}_{\beta}$ phase. The addition of CMC was a simple and effective way to disperse the cellulose fibers in the solutions without any chemical change in the BC fibers; additionally, it allowed for the production of a stable cellulose suspension after pressured vapor sterilization with potential for application in the biomedical field, such as the reinforcement or fillers of hydrogels for implants. 
Acknowledgments The authors wish to acknowledge the financial support provided by the Coordination for the Improvement of Higher Education Personnel (CAPES, Brazil), the National Counsel of Technological and Scientific Development (CNPq, Brazil), the Foundation for Science and Technology (FCT, Portugal), and also the Embrapa Tropical Agroindustry. This research study was also supported by the international collaboration Program FCT/CAPES (No. 99999.008530/2014-09).

\section{References}

Andrade FK, Alexandre N, Amorim I, Gartner F, Maurício AC, Luís AL, Gama M (2013) Studies on the biocompatibility of bacterial cellulose. J Bioact Compat Polym 28(1):97-112

Basta AH, El-Saied H, El-Deftar MM, El-Henawy AA, ElSheikh HH, Abdel-Shakour EH, Hasanin MS (2016) Properties of modified carboxymethyl cellulose and its use as bioactive compound. Carbohydr Polym 153:641-651

Briois B, Saito T, Pétrier C, Putaux JL, Nishiyama Y, Heux L, Molina-Boisseau S (2013) $\mathrm{I}_{\alpha} \rightarrow \mathrm{I}_{\beta}$ transition of cellulose under ultrasonic radiation. Cellulose 20(2):597-603

Çakar F, Özer I, Aytekin AÖ, Sahin F (2014) Improvement production of bacterial cellulose by semi-continuous process in molasses medium. Carbohydr Polym 106:7-13

Chai MN, Isa MIN (2013) The oleic acid composition effect on the carboxymethyl cellulose based biopolymer electrolyte. J Cryst Process Technol 3:1-4

Dufresne A (2012) Nanocellulose: from nature to high performance tailored materials. Walter de Gruyter Incorporated, Berlin

Gea S, Reynolds CT, Roohpour N, Wirjosentono B, Soykeabkaew N, Bilotti E et al (2011) Investigation into the structural, morphological, mechanical and thermal behaviour of bacterial cellulose after a two-step purification process. Biores Technol 102:9105-9110

Huang Y, Zhu C, Yang J, Nie Y, Chen C, Sun D (2014) Recent advances in bacterial cellulose. Cellulose 21(1):1-30

Jin-shu YANG (2014) Application of sodium carboxymethyl cellulose in food industry. Acad Period Farm Prod Process 22:027

Jonoobi M, Harun J, Shakeri A, Misra M, Oksman K (2009) Chemical composition, crystallinity, and thermal degradation of bleached and unbleached kenaf bast (Hibiscus cannabinus) pulp and nanofibers. BioResources 4(2):626-639

Kargl R, Mohan T, Bračič M, Kulterer M, Doliška A, StanaKleinschek K, Ribitsch V (2012) Adsorption of carboxymethyl cellulose on polymer surfaces: evidence of a specific interaction with cellulose. Langmuir 28(31):11440-11447

Khalil HA, Davoudpour Y, Islam MN, Mustapha A, Sudesh K, Dungani R, Jawaid M (2014) Production and modification of nanofibrillated cellulose using various mechanical processes: a review. Carbohydr Polym 99:649-665

Kose R, Mitani I, Kasai W, Kondo T (2011) "Nanocellulose" as a single nanofiber prepared from pellicle secreted by
Gluconacetobacter xylinus using aqueous counter collision. Biomacromolecules 12(3):716-720

Ku H, Wang H, Pattarachaiyakoop N, Trada M (2011) A review on the tensile properties of natural fiber reinforced polymer composites. Compos B Eng 42(4):856-873

Kurosumi A, Sasaki C, Yamashita Y, Nakamura Y (2009) Utilization of various fruit juices as carbon source for production of bacterial cellulose by Acetobacter xylinum NBRC 13693. Carbohydr Polym 76(2):333-335

Levdik I, Inshakov MD, Misyurova EP, Nikitin VN (1967) Study of pulp structure by infrared spectroscopy. Tr Vses Nauch Issled Irst Tsellyul Bum Prom 52:109-111

Li M, Wang LJ, Li D, Cheng YL, Adhikari B (2014) Preparation and characterization of cellulose nanofibers from depectinated sugar beet pulp. Carbohydr Polym 102:136-143

Li Z, Wang L, Hua J, Jia S, Zhang J, Liu H (2015) Production of nano bacterial cellulose from waste water of candied jujube-processing industry using Acetobacter xylinum. Carbohydr Polym 120:115-119

Liimatainen H, Haavisto S, Haapala A, Niinimaki J (2009) Influence of adsorbed and dissolved carboxymethyl cellulose on fibre suspension dispersing, dewaterability, and fines retention. BioResources 4(1):321-340

Matthews JF, Himmel ME, Crowley MF (2012) Conversion of cellulose $\mathrm{I} \alpha$ to I $\beta$ via a high temperature intermediate (IHT) and other cellulose phase transformations. Cellulose 19(1):297-306

Mirhosseini H, Tan CP, Hamid NS, Yusof S (2008) Effect of Arabic gum, xanthan gum and orange oil contents on $\zeta$ potential, conductivity, stability, size index and $\mathrm{pH}$ of orange beverage emulsion. Colloids Surf A 315(1):47-56

Molina-Ramírez C, Castro C, Zuluaga R, Gañán P (2017) Physical characterization of bacterial cellulose produced by komagataeibacter medellinensis using food supply chain waste and agricultural by-products as alternative low-cost feedstocks. J Polym Environ 26(2):830-837

Nascimento ES, Lima HLS, Barroso MKA, Brígida AIS, Andrade FK, Borges MF, Morais JPS, Muniz CR, Rosa MF (2016) Mesquite (Prosopis juliflora (Sw.)) extract is an alternative nutrient source for bacterial cellulose production. J Biobased Mater Bioenergy 10(1):63-70

Nelson ML, O'Connor RT (1964) Relation of certain infrared bands to cellulose crystallinity and crystal lattice type. Part II. A new infrared ratio for estimation of crystallinity in cellulose I and II. J Appl Polym Sci 8:1325-1341

Noltingk BE, Neppiras EA (1950) Cavitation produced by ultrasonics. Proc Phys Soc B63:674-685

Pecoraro E, Manzani D, Messaddeq Y, Ribeiro SJ (2008) Bacterial cellulose from Glucanacetobacter xylinus: preparation, properties and applications. In: Belgacem $\mathrm{MN}$, Gandini A (eds) Monomers, polymers and composites from renewable resources. Elsevier, Oxford, p 369

Qing Y, Sabo R, Zhu JY, Agarwal U, Cai Z, Wu Y (2013) A comparative study of cellulose nanofibrils disintegrated via multiple processing approaches. Carbohydr Polym 97:226-234

Ramli NA, Wong TW (2011) Sodium carboxymethylcellulose scaffolds and their physicochemical effects on partial thickness wound healing. Int J Pharm 403(1):73-82

Sakurada I, Nukushina Y, Ito T (1962) Experimental determination of the elastic modulus of crystalline regions in 
oriented polymers. J Polym Sci Part A Polym Chem 57(165):651-660

Segal L, Creely J, Martin A, Conrad C (1959) An empirical method for estimating the degree of crystallinity of native cellulose using the X-ray diffractometer. Text Res J 29:786-794

Sulaeva I, Henniges U, Rosenau T, Potthast A (2015) Bacterial cellulose as a material for wound treatment: properties and modifications: a review. Biotechnol Adv 33(8):1547-1571

Szymańska-Chargot M, Cybulska J, Zdunek A (2011) Sensing the structural differences in cellulose from apple and bacterial cell wall materials by Raman and FT-IR spectroscopy. Sensors 11(6):5543-5560

Tonoli GHD, Teixeira EM, Corrêa AC, Marconcini JM, Caixeta LA, Pereira-da-Silva MA, Mattoso LHC (2012) Cellulose micro/nanofibres from Eucalyptus kraft pulp: preparation and properties. Carbohydr Polym 89(1):80-88

Tsalagkas D, Dimic-Misic K, Gane P, Rojas OJ, Maloney T, Csoka L (2015) Rheological behaviour of sonochemically prepared bacterial cellulose aqueous dispersions. In: 6th International symposium on industrial engineering (SIE 2015), Belgrade, serbia

Ullah H, Badshah M, Mäkilä E, Salonen J, Shahbazi MA, Santos HA, Khan T (2017) Fabrication, characterization and evaluation of bacterial cellulose-based capsule shells for oral drug delivery. Cellulose 24(3):1445-1454

Vanhatalo K, Lundin T, Koskimäki A, Lillandt M, Dahl O (2016) Microcrystalline cellulose property-structure effects in high-pressure fluidization: microfibril characteristics. J Mater Sci 51(12):6019-6034

Vasconcelos NF, Feitosa JPA, da Gama FMP, Morais JPS, Andrade FK, de Souza MDSM, de Freitas Rosa M (2017)
Bacterial cellulose nanocrystals produced under different hydrolysis conditions: properties and morphological features. Carbohydr Polym 155:425-431

Wada M, Kondo T, Okano T (2003) Thermally induced crystal transformation from cellulose $\mathrm{I} \alpha$ to $\mathrm{I} \beta$. Polym $\mathrm{J}$ 35(2):155-159

Wada M, Hori R, Kim UJ, Sasaki S (2010) X-ray diffraction study on the thermal expansion behavior of cellulose I $\beta$ and its high-temperature phase. Polym Degrad Stab 95(8):1330-1334

Wang Y, Lian J, Wan J, Ma Y, Zhang Y (2015) A supramolecular structure insight for conversion property of cellulose in hot compressed water: polymorphs and hydrogen bonds changes. Carbohydr Polym 133:94-103

Yadollahi M, Namazi H (2013) Synthesis and characterization of carboxymethyl cellulose/layered double hydroxide nanocomposites. J Nanopart Res 15(4):1-9

Yin N, Stilwell MD, Santos TMA, Wang H, Weibel DB (2015) Agarose particle-templated porous bacterial cellulose and its application in cartilage growth in vitro. Acta Biomater 12:129-138

Zemljič LF, Steniusb P, Laineb J, Stana-Kleinscheka K, Ribitschc V (2006) Characterization of cotton fibres modified by carboxymethyl cellulose. Lenzing Berichte $85: 68-76$

Publisher's Note Springer Nature remains neutral with regard to jurisdictional claims in published maps and institutional affiliations. 